\title{
Functionalism, Normativity and the Concept of Argumentation
}

\author{
Steven W. Patterson
}

Dept. of Philosophy \& Religious Studies

Marygrove College

Detroit, MI 48221

USA

spatterson@marygrove.edu

\begin{abstract}
In her 2007 paper, "Argument Has No Function" Jean Goodwin takes exception with what she calls the "explicit function claims", arguing that not only are function-based accounts of argumentation insufficiently motivated, but they fail to ground claims to normativity. In this paper I stake out the beginnings of a functionalist answer to Goodwin.
\end{abstract}

Resumé: Dans son article (2007), «Argument Has No Function», Jean Goodwin avance des objections contre ce qu'elle appelle «les jugements de fonction explicite». Elle soutient que les théories qui attribuent des fonctions aux arguments ne sont pas justifiées et ne réussissent pas à fonder des critères normatifs pour évaluer des arguments. Dans cet article je décris les débuts d'une réponse fonctionnelle à ses objections.

Keywords: functionalism, Goodwin, normativity, social goods, rational doxastic coordination.

\section{Goodwin's case against functionalism}

In her paper, "Argument Has No Function" Jean Goodwin takes exception with what she calls the "explicit function claims" that argumentation theorists such as Walton, Johnson, and van Eemeren and Grootendorst have made (Walton 2008, Johnson 2000, van Eemeren and Grootendorst 2004). She holds that explicit function claims

...consist of the following set of assertions: (a) The context of an argument should be conceived as a joint activity. (b) That joint activity has the function of achieving a social good. (c) The norms of argument include those rules (principles, values, standards, etc.) an argument must follow (live up to, instantiate, meet, etc.) in order for the joint activity in which it is embedded to achieve its function. (Goodwin 2007.)

(C) Steven W. Patterson. Informal Logic, Vol. 31, No. 1 (2011), pp. 
After illustrating each of these three claims using examples from a number of Douglas Walton's works, Goodwin then helpfully gives the reader guidelines to help them spot when a crypto-functionalist may be lurking in their midst, by characterizing the kind of talk that signals commitment to positions like (a), (b), and (c). For example, "(a)-like talk", she tells us, is that which "name[s ] the joint activity in which arguments are said to occur, thus "baptizing" the context in which arguments are said to occur. Similarly, "using purpose language without a purpose-er" is the hallmark of "(b)-like talk". Finally, "(c)-like talk" is recognized by the invocation of an obligation to cooperate. Of each of these three kinds of talk Goodwin is skeptical. Her reasons for this skepticism are as follows.

Her skepticism of (a)-like talk, apparently, is that it seems to her strange that we should need to appeal to "abstract social institutions" in order to explain a phenomenon as familiar and as intimate to us as argumentation. ${ }^{1}$ More troubling, perhaps, is her charge that (a) ... seems suspiciously like assuming the conclusion: instead of working his way to more and more sophisticated theories of context, the theorist finds that everything he needs to know about the context of argument is already implicit in the conception of the joint activity. Let us call this Goodwin's Question-begging Charge against functionalism. If Goodwin is right about this, it is damning indeed. I will take up the question of whether she is right about this after completing the account of her reasoning against (a), (b), and (c). I now move on to her objections to (b).

Plainly put, Goodwin's first objection to (b), the claim that the joint activity of argumentation has the function of achieving a social good, is that it is assumed without any supporting evidence. Her second objection is that although it is plausible that argument has a function even in the absence of evidence, it is at least equally plausible that either (1) argument is not functional in the way that "functionalist" argumentation theorists typically assume (e.g. it may be engaged in not to resolve a difference of opinion but as a way for people to bond or cement their relationships), or (2) that argument is dysfunctional in important ways that undermine general claims about its functionality - especially in the sense of promoting hostility between persons who argue or (3) that the consequences of argumentation are not essentially connected to any sort of function. To explain this last alternative Goodwin suggests

1 From this point on, I shall use the term 'argumentation' to emphasize the process of arguing, as I believe this is in most cases consonant with Goodwin's usage of 'argument' and its cognates in her article. I am not here assuming that argumentation as such is dialectical or dialogical. Rather, I am simply focusing on the very broad range of cases in which it is. Thus, I see my task in this paper, particularly from section 2 forward as directed towards argumentation as it occurs in the "communicative context" (Pinto 2010). 
that argumentation may promote a kind of "false-consciousness" about reaching social harmony through norms of rational conflict resolution that masks deeper social realities of conflict and oppression. Goodwin's objections to (b), then, can be summed up as an Insufficient Evidence Charge, and a charge that a univocal account of the function of argumentation cannot be specified in the light of the realities of argumentative practice. Call this the Specification Charge. This leaves us with only Goodwin's objections to (c) to cover before we can move on to the replies to Goodwin's many charges. The third member of the set of assertions that comprises the account of the function of argumentation which Goodwin wishes to reject is (c): the norms of argument include those rules participants in an argument must follow in order for the joint activity in which it is embedded to achieve its function. Her section heading for this discussion nicely sums up her contention: "Even if argument has a function, we cannot derive norms from that fact." In support of this contention she gives two reasons: (1) the familiar chestnut that one cannot derive an "ought" from an "is" and (2) that argumentation doesn't seem to be the only way in which the purported functions it serves could be achieved. Let us call these two objections the Fact-Value Charge and the Necessity Charge, respectively. This ends the catalog of Goodwin's objection to the functionalist account of argumentation. It will be helpful perhaps to summarize the charges she makes against the functionalist position, which I do in Table 1. I now take up these charges.

\section{Replies to Goodwin's (a) and (b) charges}

\subsection{The question-begging and insufficient evidence charges}

Jean Goodwin's attack on functionalism in argumentation theory is powerful and convincing, and discharging her objections with anything resembling complete satisfaction would require far more depth than present considerations of space allow. Bearing that in mind, it will be perhaps wise and economical to draw out some key themes that run through more than one of Goodwin's objections and address them directly. Perhaps the most obvious theme at work is Goodwin's insistence that the functionalist lacks empirical proof for her view of argumentation. It is in evidence most clearly in the Question Begging Charge and the Insufficient Evidence Charge. Inasmuch as they are driven by Goodwin's empirical complaint, both of these charges misses an important point. The functionalist views at which Goodwin aims need not (and in some moods do not) present themselves as accurately describing the practice of argumentation as conducted "on the ground" by real agents. 


\begin{tabular}{|l|l|}
\hline Against the proposition that_, & Goodwin charges that_. \\
\hline $\begin{array}{l}\text { (a) The context of an argument } \\
\text { should be conceived as a joint } \\
\text { activity. }\end{array}$ & $\begin{array}{l}\text { The functionalist assumes this } \\
\text { where he should be proving it (The } \\
\text { Question-Begging Charge). }\end{array}$ \\
\hline $\begin{array}{l}\text { (b) That joint activity has the } \\
\text { function of achieving a social } \\
\text { good. }\end{array}$ & $\begin{array}{l}\text { The functionalist lacks sufficient } \\
\text { evidence to support this claim (The } \\
\text { Insufficient Evidence Charge). }\end{array}$ \\
\hline & $\begin{array}{l}\text { Argumentation may serve the } \\
\text { purposes named by the functionalist } \\
\text { badly or not at all, or may have } \\
\text { consequences as a social practice } \\
\text { that are unrelated to any account of } \\
\text { its function (The Specification } \\
\text { Charge). }\end{array}$ \\
\hline $\begin{array}{l}\text { (c) The norms of argument } \\
\text { include those rules an argu- } \\
\text { ment must in order for the } \\
\text { joint activity in which it is em- } \\
\text { bedded to achieve its function }\end{array}$ & $\begin{array}{l}\text { The functionalist does wrong to } \\
\text { infer norms of obligation from what } \\
\text { she takes to be facts about the } \\
\text { practice of argumentation (The } \\
\text { Fact-Value Charge). }\end{array}$ \\
\hline & $\begin{array}{l}\text { The functionalist has not esta- } \\
\text { blished that argumentation is neces- } \\
\text { sary for the achievement of the pur- } \\
\text { pose it is supposed to serve (The } \\
\text { Necessity Charge). }\end{array}$ \\
\hline
\end{tabular}

Table 1. Goodwin's Charges Against the Functionalist Position

They are, or at least charitably can be read as, largely philosophical theories whose intent primarily is to pose normative frameworks for the evaluation of some or other type of argumentation. Thus it misunderstands their purpose somewhat to complain that functionalists have not supported their account of what argumentation is. Functionalists, in the main, have not offered an account of what argumentation is. Rather, these accounts are accounts of what argumentation might be, or ought to be, or can be modeled as being. Alternatively, they could perhaps be seen as theoretical tools - merely one lens among many through which the natural phenomenon of argumentation might be viewed. ${ }^{2}$

This does not, however, mean that the functionalist is above accountability to actual practices of argumentation. Norms, after all, are addressed to actual persons and situations, and must be practicable in order to merit their being taken seriously by rational people. Just as normative moral frameworks that require saint-like altruism of agents as a matter of course are destined to break on the rocks of imperfect information and psychological and physical limitations of actual persons, so too are normative frameworks of

2 In some moods the pragma-dialectitians seem to have this general image of their own project (see van Eemeren and Grootendorst 2004, Ch.2). 
argumentation that demand of agents rational behaviors that are impossible for them consistently to exhibit. Inasmuch the question of the limits of what can and cannot reasonably be expected of agents is in part an empirical one, Goodwin's charges, particularly the Question-Begging and Insufficient Evidence Charges, retain some of their bite.

That said, however scarce the empirical evidence of the sort generated by the social sciences may be for any particular functionalist model, it is important not to overlook the fact that there are other forms of evidence, as well as explanatory and theoretical virtues, that these accounts have that can be marshaled in their defense. For example, the fruitfulness of some functionalist models - particularly that of Douglas Walton - as demonstrated by application of the model to computer science and legal studies certainly should count in favor of the view. One might, if one were so inclined, also accept the arguments produced in the course of the development of the functionalist models of argumentation as a sort of evidence for them. But perhaps this point need not be pressed. The upshot of all this is that although Goodwin may be right that there is a dearth of empirical evidence in favor of functionalist models of argumentation, and although she undoubtedly has a point in that functionalists should seek more empirical support, it is hardly the case the functionalist views are mere fancies, or castles in the sky. ${ }^{3}$ After all, the functionalist intuition itself has a long and fruitful history in philosophy and in the sciences. I will return to this notion at length in the latter sections of this paper in the course of my response to Goodwin's Necessity Charge. Good order dictates handling her other charges first however, so the Specification Charge will be taken up next.

\subsection{The specification charge}

Goodwin tells us that a univocal account of the function of argumentation cannot be specified in the light of the realities of the varied motives behind our everyday argumentative practice. How could we hold, she asks, that the purpose of argumentation is the resolution of a difference of opinion (say) when it seems clear that

Though it is clear that they have a very long way to go, there are indications that the pragma-dialectic school is at least sensitive to issues of empirical support of the kind that Goodwin raises here. It is one of the "estates" of the theory as it appears in its most recent incarnation (van Eemeren and Grootendorst 2004, 27-31) and more to the point, there is ongoing empirical work being done by various members of this school, of which (van Eemeren, Grootendorst, and Meuffels 1989) is representative. This doesn't answer Goodwin's charge as the evidence required to give the theory robust empirical support has yet to be generated but it does show that at least some functionalists aren't simply resting their case on presumption alone. 
sometimes we argue with an aim to deepening differences of opinion, to gain face (or cause others to lose it), or for more Machiavellian reasons. It is important to note at the outset that Goodwin is right in her observation that people enter into argumentation with different goals in mind. People do argue simply to impress others, or for fun, or to slow the workings of committees down when they feel things are proceeding recklessly, and for any number of other reasons in addition to the ones Goodwin herself mentions. But here it is important to distinguish between three things: (1) the reasons why an agent argues, or his or her motivation, (2) the effects that an argument may have in some particular context, and (3) the conception of what argument is for.

Goodwin's examples speak primarily to the questions of arguer's motivations and the effects that argumentation may have. These are importantly different from - and they do not allow us to draw conclusions one way or another-about what argumentation is for, about what its purpose or function is, or about whether it even makes sense to look for such a thing as a purpose or a proper function in the case of argumentation. Consider, by analogy, happening upon someone in the midst of working on his car, using a crescent wrench to beat into place a recalcitrant piece of sheet metal that has become bent out of place in the course of his work on the engine. This man uses the wrench as a hammer, but we would not say upon seeing this that wrenches have no function. The fact that one can use a heavy crescent wrench in the same fashion as a hammer in a pinch does not diminish the case for thinking that the function of a crescent wrench is the tightening of loose fasteners of a particular type. If we did draw the conclusion that the wrench had no function as such because it could be used as a hammer in a pinch, we would be mistakenly identifying the practical effect of the particular instrument in that instance with the proper function of that type of instrument. That the instrument has such a proper function is clear. There is something that it does, that it is designed to do, and that other instruments do not do as well as it does. That the instrument can be used in another way does not in any way diminish the case for thinking of it as being primarily designed to do a particular job.

The point here is not that Goodwin is conflating the user's motivation and the function of the instrument. She isn't. Rather, her examples are aimed at undermining the notion that there is a single, overarching function of argument by showing that arguing seems to have many different effects in different contexts. This is fine and we should accept it, just as we should the empirical evidence she marshals. The point is that the examples here don't show the absence of a primary or root function for argument considered as a type of socio-linguistic interaction. At best all they show is that cross-currents of arguers' motivations and the effects-intended 
and otherwise - that arguments and arguing may have in particular cases make it difficult to pick out a function for argumentation. This we should grant. It $i s$ difficult to discern a primary or central function for argumentation, but from this fact we should not draw the conclusion that the attempt to do so is in vain, or misguided. To return to the example of the mechanic, our mechanic's motivations for using the wrench could be highly variable. He may have chosen the wrench because it was heavier, or longer or sturdier, than anything else he had ready to hand for the job of beating back into place the inconveniently bent piece of body work. He might have chosen it because he thought it to be lucky, or because he thought his hammer to be unlucky, or simply because he was too lazy to go back into his garage to get the proper tool for the job. Here again, however, notice that the possible motives our man may have for using the wrench in the way that he does say nothing about what the purpose or function of wrenches is. Similarly, the effects of his using the wrench as a hammer should not deter us from speaking of the function of wrenches - even if he is successful in his "aberrant" usage of the tool, or if his usage is systematic in some way (e.g., if he always does this, or if it's quite a common thing to do). The moral of the story here, then, is that while Goodwin is certainly correct to say that people use tokens of argumentation out of different motivations and to do different things, nothing need follow necessarily from this about what the function of argumentation, understood as a type of discourse, is.

\subsection{The fact-value charge}

Even if we were to succeed in pinning down a function for argumentation, Goodwin says, we could infer nothing about the norms that would guide us in our use of argumentation. In the first place this would be to infer values from facts, and in the second place the functionalist argumentation theorist is under a (presently undischarged, she contends) burden to show us that argumentation is necessary for the attainment of the purposes claimed for it. There is a host of literature on the dispute over the Fact-Value distinction in moral philosophy, and it would be distracting to review it all here. I shall simply say instead that many philosophers, myself included, reject the fact-value distinction as spurious. ${ }^{4}$ If it is, then it cannot be the source of an objection to the notion that argumentation creates moral obligations that are binding upon

4

The reasons for this rejection are highly variable. See for example (Putnam 2002, Taylor 1989, Sturgeon 1988, Hursthouse 1999 and Jackson and Petit 1996) for five powerful and very different rejections of the fact-value distinction. I take the bankruptcy of the distinction to be over-determined by multiple considerations that emerge from these and other, similar works. 
participants in a dialogue. Goodwin's objection that, as a logical matter, facts about the function of argumentation cannot ground judgments about the morality of arguers' actions qua arguers will simply have to stand or fall with the distinction itself. Rather than becoming sidetracked with this discussion, we will perhaps be better advised to leave this matter where it stands and move on the necessity charge.

\subsection{The necessity charge}

Goodwin holds that functionalism about argumentation fails because argumentation is not necessary to produce the benefits associated with it. Let us begin with a very simple defense of the notion that functions can provide the grounds for rational criticism of a person's actions. It should suffice for this purpose briefly to return to the example of the mechanic. Suppose that our mechanic, in using his wrench like a hammer, fails to get the piece of metal back into place, and in fact makes things worse by mangling the piece. We would be right to criticize him by saying that he should have gone back into the garage for his hammer, just as we would be right to hold that a partial explanation of the failure of his action was that he had used the tool he had inappropriately. This criticism, it seems to me, would trade on perfectly normative considerations, and would be premised explicitly upon functionalistic sorts of concerns. The ground of the complaint is that he has chosen to use the wrong tool is that the tool he has decided to use has a function to which his present use does not fit. Had he used the correct tool for the job, he would have gotten the benefit of success at his task, and he would not have suffered the disbenefit of having made things worse. His inattention to the proper functions of his tools is what has brought his efforts to failure.

It is not hard to construct parallel cases where it is clear that the proper tool for the job is argumentation. For example, it is difficult to imagine a person contemplating an experimental treatment for a life-threatening chronic illness not entering into some sort of argumentation with her doctor, spouse, or close family members. If a person in these circumstances elected to choose a treatment by "poetry slam" rather than by argumentative deliberation, the same form of criticism we applied to the mechanic would apply to her too. The criticism would also be, in an important sense, right. The apparent absurdity of the suggestion that one would choose the "tool" of the "poetry slam" for the "job" of choosing whether or not to undergo an experimental treatment for life threatening chronic illness speaks volumes. Just as in the case with the mechanic, it is clear that one could do that, but equally clear that she should choose a more appropriate method of making the decision. If this advice is unheeded and things go badly 
with the treatment, it will certainly be reasonable (though gauche) to point out that perhaps a poetry slam was not the best way to make this particular decision.

The same seems to be true in any case where "getting it right" is a priority - whether or not there are multiple candidates for what "right" is in the offing. Indeed, the construction of any account that purports to model the way the world is with any degree of accuracy seems to me to require at least some argumentation, even if that argumentation is only going to occur at the level of what sorts of fact belong in the account and which do not. If this is right, and it makes sense to think that there are dialogical situations for which argumentation is a particularly apt (if not the only) choice, then it seems as if there is at least some reason to think that there is a sort of work for which arguments, like wrenches, are particularly well suited if not necessary. But one may insist that poetry slams belong on the table as an alternative means of reaching a decision. Unless the defender of argumentation can rule it out, he's left with saying that argumentation, though not the only way of making the decision, is the best or most effective on offer.

Goodwin, naturally, anticipates just this sort of defense of functionalist argumentation, and rules it out in the following quote:

The existence of functional alternatives - multiple, yet functional ways of organizing the joint activity in which arguments arise - means that a single, determinate set of norms cannot be derived from a function of argument. Now, it may be that theorists making function claims could defend their derived norms, not as necessary to achieve the alleged function of argument, but as the most efficacious or efficient way to do so. In reply I say again: Fine! But show me. How do you know that imposing on an arguer an obligation to answer just these objections optimally promotes the mutual understanding, the rational resolution of disputes, or any other posited social good? (Goodwin 2007, 83.)

The objection made in this paragraph calls upon the defender of functionalism in argumentation to show all of the following:

1. That argumentation has at least one function which it performs more efficiently or effectively than any other, similar alter-native.

2. That this function is the production of some sort of social good.

3. That the production of this social good grounds obligations that bind arguers to do things like answer objections, etc. 
4. That holding arguers to these obligations is necessary in order to produce the social good that it is the function of argu-mentation to produce.

$5 . \quad$ That we know all of this.

Answering all of these challenges is a tall order, and quite a lot turns on two critical points. The first of these concerns the way in which arguments can be said to have a function, and the path one takes from considerations about functions to considerations about normativity; the other concerns the social good to which argumentation is said to serve. It is to these tasks that the next section of this paper is addressed.

\section{Functions and norms in argumentation}

\subsection{Argumentation as a social practice}

Argumentation is a subspecies of communication and is therefore, by definition, a social activity. Argumentation is more than just some vague social happening, however. One way of understanding the functionalist intuition is to say that it is a practice. What does it mean to say that argumentation is a social practice? There are differing accounts of argumentation as practice in the literature. ${ }^{5}$ For my part, I want to hold that it means at least the following:

1. Argumentation is first and essentially something in which multiple agents engage. Individual agents may argue "with themselves", but only in a derivative sense.

2. Argumentation is a rule-guided (or alternatively, a norm-guided) activity that takes place in the context of a large background of social and other understandings and facts.

3. Argumentation has a telos that it serves better than alternative modes of linguistic social interaction. This telos is its function.

A few remarks are in order about each of these assertions, beginning with the first.

\subsubsection{Argumentation is properly social}

An observation that is entirely unremarkable among argumentation theorists, but whose significance has yet to garner the attention it deserves among philosophers and social scientists

5 See in particular Johnson (2000) and van Eemeren and Grootendorst (2004). 
outside of argumentation theory is that to argue is fundamentally and primarily a social activity. The notion of the single thinker, sitting silently before the fire and deliberating to himself about whether or not he has a body and a soul, or about whether or not he should join the army or the priesthood can give the mistaken impression that argumentation is a solipsistic process. To the contrary, Christina Slade has argued that the fact that we think in "inner" dialogues in which we pose and answer various points to ourselves as our own shadowy interlocutor; that we "argue with ourselves" about important decisions is revealing as to the inherently social nature of the activity of arguing (Slade 1995). If we did not argue with others, she suggests, we would be incapable of arguing "with ourselves". The point here is not to rule one way or the other on Slade's thesis but to follow her lead in emphasizing and taking seriously the social nature of argumentation. Accordingly we do well to think of argumentation on analogy with ballroom dancing or, to borrow an example from Taylor (1995), sawing a log with a two-man saw.

\subsubsection{Argumentation is rule-guided}

The second of the three propositions given above requires a bit more explanation. Argumentation is marked off from other sorts of linguistic practices by being primarily about the exchange of reasons. These can be reasons for thinking or reasons for doing. We argue that some or other sentence or proposition is true (or false) or that some action is worth doing (or not worth doing). Regardless of whether the issue of the argumentation is the epistemic status of a proposition or the choice of an act, however, we commonly give and expect to be given reasons that are pertinent and that aid in moving the discussion to an appropriate terminal point with respect to the issue. ${ }^{6}$ The rules involved in the practice of arguing are those that figure into our ability to recognize modes of speech and types of consideration that alert us to the fact that we are being argued with (as opposed to, say, merely being politely coerced) and those by which we choose correspondingly appropriate modes of speech and types of consideration to advance vis-à-vis our end of the discussion. They guide us to those modes of speech and action that are most effective for the clear exchange of reasons between rational agents.

I wish to stress that the relationship of the rules or norms to the practice is a complicated one. The rules are not to be understood as fixed and immutable laws that constitute the practice of argu-

$6 \quad$ The terminus need not be resolution of the issue, conceived of as all parties adopting the same position with respect to it. I shall have more to say about this in section 4 of this paper. 
mentation in a one-directional way. Rather, they evolve as the practice evolves, and the practice evolves with the situations to which it is adapted. The relationship between the rules or norms and the practice itself is one of reciprocal influence. Charles Taylor's description of the relationship between rules and practices sums up nicely the point I am trying to make:

What is on paper a set of dictated exchanges under certainty, on the ground is lived in suspense and uncertainty. [The rule] doesn't apply itself; it has to be applied, which may involve difficult and finely tuned judgments. This was the point made by Aristotle, as basic to his understanding of the virtue of phronesis. Human situations arise in infinite varieties. Determining what a norm amounts to in any given situation can take a high degree of insightful understanding. Just being able to formulate rules will not be enough. The person of real practical wisdom is less marked by the ability to formulate rules than by knowing how to act in each particular situation. There is a crucial "phronetic gap" between the formula and its enactment, and this too is neglected by explanations that give primacy to the rule-as-represented. [...] Practice is, as it were, a continual interpretation and reinterpretation of what the rule really means. [...] That's why the rule is, at any given time, what the practice has made it. (Taylor 1995, 177-8.)

The background of social understandings and facts about the world against which the practice of argumentation has its life is what necessitates the continuing evolution of the rules and norms that guide argumentation. ${ }^{7}$ Discovering exactly what the rules are, then, has to be thought of as an ongoing study, the subject of which is something of a moving target. Whatever the rules or norms turn out to be, they will be somewhat plastic. Plastic though they may be, though the rules should be yet firm enough to mark argumentation off from other linguistic practices. This is why they belong in an accounting of argumentation as a social practice.

Of course nothing has been said about what the rules of argumentation actually are at this point. This is for three reasons. First of all, considerations of time and the reader's patience forbid the extensive digression it would take to even begin such a discussion in this paper. Secondly, the actual shape of the rules is somewhat moot. It is enough to make the point that argumentation is a social practice that one observes the Wittgensteinian principle

This point is also made--and illustrated byconcrete political examples--in Kornprobst (2007). 
that any rule-guided endeavor is inherently social. Thirdly, whatever the rules are they will be best explained in terms of their connection to the telos of argumentation. ${ }^{8}$ This brings me to the third proposition in my sketch of the social practice of argumentation.

\subsubsection{Argumentation has a telos}

First, a clarification. The word 'telos' carries with it some ambiguity. In the sense that Aristotle uses it across works such as the Physics, Metaphysics, and Nicomachean Ethics, it means "end"that for the sake of which a thing is. In Aristotle's metaphysics and ethics this notion of telos is importantly connected with the idea of ergon, or function. This is most easily grasped in the case of artifacts where, for example, the telos or end of the clay vessel is the ergon or function of holding wine. It also applies to occupations, where we might say that cobblers exist for the sake of shoes, which it is their function (within a system of divided labor) to produce and maintain. It is in this same sense that I wish to claim that argumentation has a telos. Argumentation exists for the sake of a good that it is its function to produce and maintain. Just what that good is I shall come to in the next section, but it is important first to motivate the notion that argumentation has a telos in this way at all.

The proposition that argumentation has a telos of its own is, I think, intuitive. One reason it is intuitive is because of the prevalence of normatively-guided practices of argumentation across diverse human cultures. Argumentation is not something that only Western cultures do or have done. There are indigenous traditions of argument (and logic) in cultures as different from Western culture as India and China. Where human beings have used language and their societies have flourished, people have argued. Thus argumentation, like other communicative innovations like poetry, storytelling, and symbolic painting, seems to answer a need that human beings have that transcends the particularities of culture, language, or social, historical, or temporal context. ${ }^{9}$

This reason suggests another: If we accept in its outline the notion that argumentation is a form of communication that at times plays a role in decision making, and if we grant, as we most surely should, that human beings have other modes of communication and other modes of decision making then the question naturally arises

\footnotetext{
I focus on the normative aspect of argumentation explicitly in (Patterson 2010).

For an overview of traditional forms of argumentation in diverse cultures see Harpine (1993). For a contemporary account of argumentation across cultures see Liu (1999).
} 


\section{Steven W. Patterson}

as to why we would still have argument in addition to these other communicative practices. Why has argumentation not been eclipsed by storytelling, or decision-making by, for example, fiat of the eldest in the tribe? Surely it could have gone that way. Why did it not? It will not do here to tell a tale of colonial imposition of "Western" norms of reasoning and argumentation on other cultures because, as we have already noted, other cultures had (and continue to have) indigenous modes of argumentation. Further, some cultures have explicitly adopted "Western" modes of argumentation of their own volition because of a felt need on the part of at least some members that Western modes of argumentation were complementary to their own. ${ }^{10}$ Argumentation then, it seems clear, has persisted side-by-side with apparent functional alternatives for some time without waning as a practice. Not only has argumentation held its own, it has developed into more and more sophisticated variations over time, many of which are represented in the different disciplinary and theoretical orientations that comprise the contemporary study of argumentation itself.

Knowing as we do that when human beings retain a practice over a long period of time that there is usually an explanation that appeals to its ability to produce a certain socially desirable good or state of affairs, it seems that all this indicates that there is a good prima facie case that argumentation provides something to human beings that other forms of communication do not, or at least that other forms of communication do not provide as well. There is therefore some intuitive ground for the attempt to give a functionalist account of argumentation. Goodwin would, I believe, admit as much. For her claim is not that argument doesn't have any function, it is that argument does not have a single function that could ground the normativity of any purported system of rules for arguers. Answering that charge requires the development of an account of the social good that gives argumentation its telos.

\subsection{The social good of argumentation}

Most theoretical accounts of argumentation justify the practice by appeal to some or other social good of which it is productive. Many of these accounts are now quite familiar among argumentation theorists. For example, Ralph Johnson holds that the good is the manifesting of rationality (Johnson 2000). Harvey Siegel maintains that argumentation provides us with better-justified beliefs (Siegel 1997). The pragma-dialecticians hold that argumentation, in some iterations at least, resolves our differences of opinion (van Eemeren and Grootendorst 2004). Douglas Walton's view is similar to this

10 (Suzuki 2008) makes an interesting case that this is exactly what happened in Japan, for instance. 
one (Walton 2008). There are, of course, other views. Toulmin held that argumentation is primarily about the justification of assertions (Toulmin 2003, 12). Perelman and Olbrechts-Tyteca and following them, broadly speaking, Tindale, hold that it aims to increase the adherence of an audience to a thesis (Perelman and OlbrechtsTÿteca 1969, 45; Tindale 2004). Still others, like Kauffeld, hold with Goodwin $^{11}$, that argumentation is essentially and importantly heterogeneous in its purposes (Kauffeld 2007). Many of the accounts just mentioned overlap with one another in important ways. Given this diversity of opinions about what argumentation does for people, if functionalism about argumentation is to be defended then, in addition to being clear about what 'functionalism' means in this instance, we must also be able to articulate the good that is the end result when the function of argumentation is realized. I wish to begin by noting an implication of the aforementioned overlap between many accounts of the good produced by argumentation. The central observation here will be that lying underneath them all is a single umbrella good to which each, in its own way, conduces. ${ }^{12}$ The general good to which all these views conduce I shall call rational doxastic coordination. I maintain that it is the function of argumentation to produce this good. Rational doxastic coordination is one species of a much broader genus, about which a few preliminary remarks are in order.

\subsubsection{Doxastic coordination}

Doxastic coordination is just what it sounds like: the bringing into equilibrium or harmony of the opinions or beliefs of multiple persons, without respect to the means employed. The goodness of doxastic coordination is largely social and largely pragmatic. When people are closer together in their opinions, or at least feel that they are, it is easier for them to sustain cooperative attitudes towards one another in a wide variety of settings. Indeed, it is hard to imagine any social activity-even primitive activities like hunting or gathering, building shelters, or conducting warfare coming to a successful end without it. Doxastic coordination seems to be at least one reason why we communicate with others at all.

That said, it is clear that not all forms of communication will be productive of doxastic coordination, or to the same degree. Some will do better than others, and which ones will do better will depend partially on factors such as social, historical, and cultural

"I strongly endorse the functionality (purposiveness, usefulness, value, effectiveness, dignity) of argument in this broad sense. The functionalism that I am objecting to, by contrast, is a specific mode of theory construction-a specific way of modeling the general functionality of argument" (Goodwin 2007, $70)$.

12 My strategy here is an echo of that James Rachels uses for defusing the relativistic import of cultural differences (Rachels 1978). 


\section{Steven W. Patterson}

context, the facts of the situation at hand, the opinions and capabilities of the individuals involved, and so forth. Human life is as heterogeneous by nature in its circumstances as human beings are heterogeneous in their aims. Given the importance of doxastic coordination for cooperative and coordinated activity, and given the importance of such activities for human survival it would be absolutely shocking if there weren't multiple pathways to reaching it. Some might involve the communal acceptance (and regular reaffirmation) of a particular myth or other narrative (that of the gods, say) to remove solidarity-undermining uncertainty and provide a shared explanatory framework from which all can draw and make themselves understood. To be specific as to means, might call this narrative doxastic coordination. A different means might involve the learning and repetition of a code of belief-like the Apostle's Creed or the Ephebic Oath of Athens - to which one commits (and recommits) in a regular, public way. Such codes are not narratives, but a distillation of what is taken to be the common principles and beliefs around which our beliefs and actions, both individually and collectively are to be structured. This would be promissory, or perhaps even contractual doxastic coordination. In addition to myths and oath-taking, another way of achieving doxastic coordination might simply be violence - the extermination of unbelievers or the threatening of force as repayment for dissent leaves a group with doxastic coordination by default, if at a terrible price - call this repressive doxastic coordination. There are doubtless many other members of this family including, as we shall see, rational doxastic coordination. For present purposes however, the point is that all of these different modes are linked in that they function, among other things, to produce equilibrium in the beliefs or opinions of multiple individuals.

Inasmuch as doxastic coordination is seen as an effect of argumentation, there is reason to think Goodwin would find the account developed agreeable. For, her critical point is not that argumentation does not produce goods, but that argumentation isn't necessary to produce those goods. (Goodwin 2007, 83) And so long as we restrict the focus to doxastic coordination simpliciter, she is right. There are other ways of achieving doxastic coordination, and argument isn't necessary. But if argumentation isn't necessary for doxastic coordination, then why do human beings, in all their diversity and with all the alternatives available, still have, use, and value it? The answer to these questions, I submit, is that argumentation generates doxastic coordination of a particularly valuable species: rational doxastic coordination. ${ }^{13}$

13

Note, however, that to say that rational doxastic coordination is particularly valuable is not to commit oneself to the position that rational doxastic coordination is categorically superior to other forms. Indeed, I wish to 


\subsubsection{Rational doxastic coordination}

The idea of rational doxastic coordination has an antecedent in a 1987 conference presentation by Josef Kopperschmidt entitled "The Function of Argumentation: A Pragmatic Approach". Kopperschmidt writes (my emphasis):

Argumentation ensures the communicative conditions for the existence of people, living in a society and dependent upon cooperation, if the coordination of actions no longer can be based on a common view of the world and if a shift for mechanisms for such coordination, which is independent of understanding, has not yet functioned and perhaps, in principle, never will [...] Arguments are therefore necessary...because they ensure conditions for understanding between people in problem situations. (Kopperschmidt 1987, 179-181.)

Kopperschmidt's view here is broadly Habermasian. I want to understand the function of argumentation just a little more broadly. The reason for this is that restricting the usefulness of argumentation to establishing "conditions for understanding between people in problem situations" seems too broad. Depending on how one interprets 'conditions' it seems to me plausible to think that any sort of doxastic coordination could do that. Another consideration that makes this formulation somewhat problematic is that persons do not only argue in "problem situations". They may argue, for example, when they simply want to know something even though nothing of immediate practical consequence hinges on their investigations. ${ }^{14}$ We can preserve much of what is good in Kopperschmidt's notion if, instead of thinking in terms of problem situations, we understand what rational doxastic coordination means in terms of the metaphor of mapping. ${ }^{15}$

resist that inference, as I hold that the different means of rational doxastic coordination can be and often are mutually supporting. This perhaps is a difference between the position I advocate in this paper and that of some of the functionalists against whom Goodwin sets herself.

14 Of course one can construct this as "problem situation" but I am wary of a looming circularity here wherein what it is to be a problem situation is defined just in terms of a situation's being an occasion for argument, and what it is to be an argument is to be the kind of thing one deploys to resolve a problem situation. I am also unsure at this point that even if this circularity can be avoided, the concept of a problem situation is itself can be made clear in a way that does much work. This is why I prefer the metaphor of mapping instead, although I recognize that this may make readers no happier than talk of "problem situations"!

15 My use of this metaphor follows, roughly speaking, that of Simon Blackburn (Blackburn 2005). 
Let us imagine that claims in language (and the beliefs on which they are based), when sincerely put forward, broadly speaking are claims about the way things are in the world. Such claims are like proposed linguistic maps of a commonly experienced territory. They amount, metaphorically, to an assertion that "This is what the terrain looks like from where I am." Rational doxastic coordination, then, should be understood as bringing individual "maps" of the territory into sync in two ways: (1) such that the dissonance caused by differences between individual maps is explained or minimized (e.g., "you cannot see the tree that I see because that rock is blocking your view") and (2) such that the individual maps as well as the (intersubjective) "community map" better corresponds to the territory at issue (e.g. the composite of all of our maps now contain the tree and the rock regardless of where we stand in relation to them). I submit that argumentation is the process by which we do this. It is what argumentation is uniquely suited to do.

The other forms of doxastic coordination discussed in the previous section all employ means that are more or less indifferent to the cognitive alignment of individual beliefs. They achieve equilibrium between the doxastic states of persons through means that bear little intrinsic connection to In narrative doxastic coordination, for example, it really doesn't matter if the narrative on offer is true (whatever that might mean for narratives), so long as it is sufficient to bring equilibrium to the beliefs and attitudes of the persons who adhere to the narrative. What matters is not that Zeus or Thor is real, say, but that the narrative is one that a critical mass of us can accept at a very basic level (i.e. does no psychological or apparent logical violence to one's unreflective, "commonsense" experience of the world), and one to which shared allegiance produces the benefit of enhanced cooperative potential.

It is important to notice that we need not find ourselves in a "problem situation" in order to find this function salutary. Though it is true that we may have a problem that motivates us to seek to resolve a difference of opinion, such resolutions are only one type of rational doxastic coordination. We may not disagree at all, but simply wish to strengthen our understanding of a position or phenomenon by subjecting it to investigative scrutiny. We may wish to "map" a previously "unmapped territory"--to generate an account of a hitherto unexplained or anomalous fact. Alternatively, we may need to coordinate ourselves in a for social or political reasons rather than epistemic ones, as when organizing politically for an election or referendum, or for purely practical reasons, as in deliberations about which movie to see, or to which school to send the children, or how best to get a sofa up several flights of steps. ${ }^{16}$ 
Some may find the metaphor of mapping to be too vague to explain rational doxastic coordination. One way of capturing the general idea would be to think of the effect of argumentation as an increased consistency between the commitment stores of all agentparties to the argumentation (Walton and Krabbe 1995). Another way would be to think in terms of Robert Pinto's notions of direct and oblique effects of argument (Pinto 2010). Both of these accounts capture, at least partially, what it means for our "maps" to be in sync. It is important here to note that neither of these proposals for understanding rational doxastic coordination requires that the endpoint of argumentation necessarily is agreement about the thesis under question. That may result but it needn't. Rational doxastic coordination will be achieved if the participants' beliefs move closer together on any point whatsoever. Even if the participants leave the argumentation episode unpersuaded, but with a clearer understanding of each other's views, then that is enough to count. It will be enough if they simply understand each other and each other's arguments better. To return to the metaphor of mapping, in such a case the participants' "maps" may not gain in the size of the territory they cover, but they may gain in the level of detail they show.

The idea of rational doxastic coordination is a unifying idea. It is aimed at showing how apparently disparate functions of argument are really all members of the same family by showing what it is that they all have in common; the common destination towards which they all lead by varying degrees. Thus it is important that the idea of rational doxastic coordination be consistent with all of the accounts of the purpose of argument with which this section began. I believe that it is. Those who hold that the purpose of argumentation is to gain adherence for a thesis can be understood as holding that the speaker's goal is to bring the beliefs of his audience into harmony or equilibrium with his own. Those who hold that the purpose of argumentation is the resolution of a difference of opinion can be understood in the same way, as the difference of opinion, on those views, is resolved when the opinions of the parties have converged on a single alternative. Those who hold that the purpose of argumentation is to produce justified beliefs have perhaps the most direct linkage to the value of doxastic coordination, since there could be no more efficacious point of convergence for persons than upon the truth about the world, or about a particular state of affairs in that world to which they must address their actions.

Argumentation then, if the preceding is correct, exists for the sake of rational doxastic coordination, the production and 
maintenance of which is its function. Where rational doxastic coordination is what we seek, argumentation is the instrument of choice. This does not mean, however, that the other kinds of doxastic coordination of the sort described in section 3.2.1 are inferior or to be devalued. On the contrary, we may need such means of bringing about social solidarity in order to make it "safe" to argue with one another at all. The trust necessary for a candid and sincere deployment of argumentation in the pursuit of resolving some difference of opinion, or for making a difficult and painful decision is not automatic. That said, it will not do to collapse rational an non-rational forms of doxastic coordination. If the round of argumentation is successful in its aim and has been conducted in the right way, then it is imminently reasonable to expect argumentation to enhance the social bonds among those who were parties to it. But however desirable this may be it is an effect of the argumentation, not its function in the proper sense. We may hope that this will happen, but it is not what arguments specially are for. In this respect arguing is like baking. Baking can have beneficial (or harmful) effects that outrun the primary reason one does it (for the cake!), as when the heat from the oven makes the house warm, or fills the room with a pleasant aroma. By the same token, careless or inexpert baking can also have disastrous effects that we do not intend or desire (e.g., if one burns the house down, or the product is inedible and the company is at the door, etc.). The same is true of argument. The fact that argumentation can have pleasant by-products or, if it is abused or engaged in maliciously or incompetently, can have unpleasant consequences need not weaken the notion that there is something that argument is for in an important sense. This "what it is for" is rational doxastic coordination. It is the proper function of argumentation (pictured as one part of the overall system of human communication) to give rise to it, even if there are side effects at times. But even if we assume that this is correct and argument has a function, how does that function give rise to normativity?

\subsection{Functions and normativity}

The functionalist intuition is one of the oldest in philosophy, going back at least to Aristotle if not before. It underlies some of the most important and fruitful explorations in the history of philosophy, from Peirce's pragmatism to twentieth-century philosophy of mind. In the case of the latter, the functionalist intuition has proved incredibly powerful not just for philosophical but for scientific approaches to the study of mind and cognition as well, and these effects have branched into what is now a very robust program of research into artificial intelligence in the fields of computer science 
and programming. Functionalism in all of these fields has faced, and continues to face very strong objections, but in the main these objections have been weathered successfully enough to keep functionalism alive and prospering in those fields where it has been most productive. Indeed, it has been successful enough that the idea of applying it to new fields has seemed a good one to many contemporary philosophers.

In a recent paper Robert Brandom suggests that the normativity within functional accounts of intentionality can be brought out by counterfactual analysis. Brandom makes the point forcefully with an illustration from recent work by Dretske and Millikan on biologically inspired functionalist programs that aim to "naturalize" the field of semantics. Brandom takes it as a key moment in the historical lead-up to these programs that there has been

...a heightened appreciation of the normative character of meaning and concept use aroused in part by Kripke's discussion of Wittgenstein, beginning in the early '80s. The core idea is that anything recognizable as an intentional state...must underwrite normative assessments as to whether things are as they ought to be, according to that state--whether the state is correct or successful according to the standards determined by its content. (Brandom 2001, 589.)

This way of thinking about intentional states, Brandom argues, has given rise to the project of "understanding the normativity of intentionality by appealing to norms of proper functioning of representings relating them to representeds modeled on norms of proper functioning of reproducing biological systems that evolved by natural selection" (Brandom 2001, 593).

The upshot of all this is that if we want to understand the normativity inherent in an intentional state, we can do so by asking ourselves what the proper function of that state is, and what the world would have to be like in order for us to say that the state is functioning correctly (or incorrectly). Consider the example of a simple perceptual belief. Let us suppose that Larry believes that there is a finch on his railing. On the analysis on offer here, his epistemic faculties of belief are functioning correctly only if we can say counterfactually that, under ordinary conditions, if there were no finch on his railing then (pro tanto) he would not have believed that there was. We make this judgment on the basis of our holding that perceptual and epistemic faculties have evolved over time in creatures like us to help us get into a fruitful cognitive relationship with the world by representing it to ourselves in more or less the way it actually is. Thus, if our belief-producing faculties are working correctly, then they ought to give us a more-or-less 
rationally endorsable, first approximation of the way the world is. It follows that if Larry's powers of perception and belief formation are working as they should and there are no environmental conditions present that would frustrate their functioning, then there is in all likelihood a finch on his railing.

Now, of course he might be wrong in forming this belief - it may be some other bird that is hard to distinguish from a finch, or he may have left his glasses on the table, or something else may have interceded to disrupt the usually reliable process by which he forms beliefs on the basis of sensory perceptions. None of these possibilities undercuts the functionalist explanation of belief states unless it can be shown to happen in a systematic way. Functionclaims relate to types of intentional states, not to tokens. So the failure of any one token, especially when explicable in ready-tohand causal terms gives us no special reason to doubt the function claim about the type. (Indeed, the full story about the interrelatedness of functionalistic intentional states like belief and other faculties like perception would to my mind require an account of how, in some instances, tokens of belief fail in their function.)

How does all of this apply to arguments? I have argued that argumentation is a rule-guided social practice the function of which is to produce rational doxastic coordination, in the form of diminished inconsistency in the commitment stores of agentparties. If this account of the function of argumentation is correct, then argumentation functions properly only when it produces rational doxastic coordination. This, on the current account, is what the practice of argumentation has evolved over time to do for creatures like us. Notice that, just as with intentional states, this sort of account does not require that argumentation is always successful in its function. Just as is the case with the formation of perceptual belief, argumentation is not infallible. It is possible for the function not to be realized in particular tokens of argumentation, without there being any subsequent damage to the function claim about the argumentation as a type. The account of the type would only be in trouble if argumentation as I am defining it here were to turn out to fail systematically to produce rational doxastic coordination - that is, if we almost never understood each other better in any of the ways suggested (or alluded to) in section 3.2.2 after engaging in argumentation with one another.

Just as the faculty by which we form perceptual beliefs, in my admittedly very crude example, helps an individual to get into a better cognitive relationship with her environment, the practice of argumentation helps plural individuals get into a better cognitive relationship with each other and with (one hopes) the environment that they share. The "rules" of argumentation then are a body of so much accumulated best practices and rules of thumb that have served to produce this result in the past. They are, in a not 
insubstantial sense, an inheritance from the arguers of the past, having been shaped by their argumentative successes and failures in the conditions under which they argued. Something similar happens with perceptual belief. Over time, the attentive, wellpracticed agent gets better at forming beliefs about what she sees as she learns how her various faculties are influenced, and at times compromised, by the conditions under which her beliefs are formed. As those who wish to have appropriate beliefs about the world should seek to have beliefs that at least rationally approximate the way the world really is, those who wish to argue appropriately should seek to do so in a way that conduces to rational doxastic coordination with their interlocutors. ${ }^{17}$ Therein, I suggest, lies one vector of the normativity of the rules that are taken to guide the conduct of arguers.

\section{Conclusion}

The account I have offered here, I believe, offers at least the beginnings of an answer to all of Goodwin's objections. In emphasizing the philosophical and theoretical nature of the functionalist project, I have managed to forestall Goodwin's first two complaints, first that the functionalist assumes what she should be proving, and second that she lacks evidence. The key to answering both of these complaints is to recast the functionalist project in a slightly more charitable light. The functionalist should not be interpreted as having attempted to establish an empirical claim about what argumentation is by philosophical fiat. Any functionalist, including myself, remains accountable to the data. That said, it misses the point of a theoretical model to complain that it is insufficiently established by empirical evidence. For the point of having a theoretical model in the first place is to provide the empirical researcher with something to confirm or disconfirm. If this is right, then the question begging and insufficient evidence charges need not concern the functionalist until and unless conclusively falsifying data comes in.

To Goodwin's third charge that the effects of argumentation are too heterogeneous for there to be just one function that argumentation can be thought to serve, I have introduced a distinction between the arguer's motive, the effect of a given argument, and the function of argument that explains the apparent heterogeneity while still leaving space for there to be an overarching function of argument.

17 'Appropriate' here is intended to indicate the perhaps uninteresting sort of belief that serves us at a very basic level; that has pragmatic efficacy largely because it accurately maps onto the world we inhabit. 
Passing over the fourth objection about the fact-value distinction, I have devoted the bulk of my remarks to showing that argumentation is necessary to achieve the good that is its unique function to produce. Here I have offered an account of the social practice of argumentation that sees its function as the production of rational doxastic coordination, and grounds the normativity of the rules of argumentation in that function via a speculative account of why argumentation would have arisen and persisted among creatures like us. I wish to make it clear that I have only offered an outline of this account. I have not yet argued for it. That remains to be done. Inasmuch as I have not done this, the fifth and final plank of Goodwin's necessity charge, that demands that the functionalist account for how he knows that argumentation does what his account says it does, remains unanswered.

Acknowledgements: I owe a great debt first to Jean Goodwin, who put me on to the interesting question of whether or not argument might have a function. I am also very grateful to the members of the Centre for Research in Reasoning, Argumentation and Rhetoric (CRRAR) at the University of Windsor for their support during my tenure as a Visiting Research Fellow. Those who attended the CRRAR colloquium session at which this paper was first presented offered many comments, critiques, and challenges both during the session and after that helped the development of the ideas in this paper immensely. I am particularly indebted to Robert Pinto with whom my conversations on these and other matters have proven to be consistently enlightening.

\section{References}

Blackburn, S. (2005). Truth: A Guide. Oxford: Oxford University Press.

Brandom, R. (2001). Modality, normativity, and intentionality. Philosophy and Phenomenological Research 63 (3), 587-609.

Eemeren, F.H. van \& Grootendorst, R. (2004). A Systematic Theory of Argumentation: The Pragma-Dialectical Approach. Cambridge: Cambridge University Press.

Eemeren, F.H. van, Grootendorst, R. \& Meuffels, B. (1989). The skill identifying argumentation. The Journal of the American Forensic Association 25, 239-245.

Goodwin, J. (2007). Argument has no function. Informal Logic 27 (1), 69-90.

Harpine, W.D. (1993). The appeal to tradition: cultural evolution and logical soundness. Informal Logic 15( 3), 209-219.

Hursthouse, R. (1999). On Virtue Ethics. Oxford: Clarendon Press. 
Jackson, F. \& Petit, P. (1996). Moral functionalism, supervenience, and reductionism. The Philosophical Quarterly 46 (182), 8286.

Johnson, R.H. (2000). Manifest Rationality: A Pragmatic Theory of Argument. Mahwah, NJ: Lawrence Earlbaum Associates.

Kauffeld, F.J. (2007). Two views of the necessity to manifest rationality in argumentation. In Hans V. Hansen (Ed.), Dissensus and the Search for Common Ground. CD-ROM. University of Windsor, ON: OSSA.

Kopperschmidt, J. (1987). The function of argumentation: a pragmatic approach. In Frans H. van Eemeren, Rob Grootendorst, J. Anthony Blair, and Charles A. Willard. (Eds.), Argumentation: Across the Lines of Discipline. DordechtHolland: Foris Publications, 1987, pp. 179-188.

Kornprobst, M. (2007) Argumentation and compromise: Ireland's selection of the territorial status quo norm. International Organization 61 (1), 61-98.

Liu, Y (1999) Justifying my position in your terms: cross-cultural argumentation in a globalized world. Argumentation 13, 297315.

Patterson, S. (2010) Dancing, dueling, and argumentation: on the normative shape of the practice of argumentation. Forthcoming: Proceedings of the Seventh Conference of the International Society for the Study of Argumentation, University of Amsterdam, the Netherlands.

Perelman, C. \& Olbrechts-Tyteca, L. (1969). The New Rhetoric: A Treatise on Argumentation. Notre Dame, IN: The University of Notre Dame Press.

Pinto, R.C. (2010). The uses of argumentation in communicative contexts. Argumentation 24, 227-252.

Putnam, H. (2002). The Collapse of the Fact-Value Dichotomy and Other Essays. Cambridge, MA: Harvard University Press.

Rachels, J. (1978). Elements of Moral Philosophy. New York: McGraw Hill.

Siegel, H. (1997). Rationality Redeemed? Further Dialogues on an Educational Ideal. New York: Routledge Publishing.

Slade, C. (1995). Reflective reasoning in groups. Informal Logic 17 (2), 223-234.

Sturgeon, N. (1988). Moral explanations. In Sayre-McCord, G. (Ed.), Essays on Moral Realism. Ithaca, NY: Cornell University Press.

Suzuki, T. (2008). Japanese argumentation: vocabulary and culture. Argumentation and Advocacy 45, 49-53.

Taylor, C. (1995). Philosophical Arguments. Cambridge, MA: Harvard University Press.

Taylor, C. (1989). Sources of the Self. Cambridge, MA: Harvard University Press. 
Tindale, C. (2004). Rhetorical Argumentation: Principles of Theory and Practice. Thousand Oaks, CA: Sage Publications.

Toulmin, S.E. (2003). The Uses of Argument. New York: Cambridge University Press.

Toumela, R. (2007). The Philosophy of Sociality: The Shared Point of View. New York: Oxford University Press.

Walton, D. (2008). Informal Logic: A Pragmatic Approach. New York: Cambridge University Press.

Walton, D.N. \& Krabbe, E.C.W. (1998). Commitment in Dialogue. Albany, NY: State University of New York Press. 